\title{
VICO Y LOS ALBORES DE LA EXPERIENCIA JURÍDICA
}

\author{
Fernando H. Llano Alonso \\ (Universidad de Sevilla)
}

\begin{abstract}
RESUMEN: El presente capítulo comienza con una semblanza iusfilosófica de Vico, pensador germinal que consiguió unir primorosamente la Filosofía y el Derecho. A partir de esa premisa el Autor del mismo evoca sus años de formación doctoral y sus inicios en el estudio de la Historia del pensamiento jurídico de la mano de Guido Fassò, acaso el más viquiano de los iusfilósofos italianos. Finalmente se reivindica la importancia de Vico para la Teoría del Derecho moderna, pues al pensador napolitano le debemos, entre otras cosas, su importante contribución a la doctrina de la experiencia jurídica, su aportación fundamental para la renovación del iusnaturalismo a través de la dimensión histórica, así como la influencia de su obra jurídica para la rehabilitación de la tópica y la metodología del Derecho.

Palabras ClaVe: Vico, $350^{\circ}$ Aniversario, Teoría del Derecho, experiencia jurídica, Derecho natural, Historia de la Filosofía del Derecho, tópica, metodología del Derecho, G. Fassò, F.H. Llano Alonso.
\end{abstract}

Vico and the dawning of legal experience

ABSTRACT: This chapter starts with a biographical sketch of Vico from the philosophy of law standpoint; he was a seminal thinker who got to skillfully unite Philosophy and Law. From this premise its Author evokes his years of $\mathrm{PhD}$ training and his beginnings in the study of the history of legal thought, guided by Guido Fassò, perhaps the closest to Vico of the Italian legal philosophers. Finally Vico's importance for the modern Theory of Law is vindicated, since we owe the Neapolitan thinker, among other things, his important contribution to the doctrine of the legal experience, his key participation in the renovation of natural law through the historical dimension, as well as the influence of his legal work for the restoration of the topics and legal methodology.

KEYwords: Vico, 350 th Anniversary, Theory of Law, legal experience, Natural Law; History of Legal Philosophy; topics; legal methodology, G. Fassò, F.H. Llano Alonso.

\section{Vico e gli albori dell'esperienza giuridica}

RiASSUNTO: Il presente capitolo inizia con un profilo "iusfilosofico" di Vico, pensatore germinale che riuscì ad unire in modo eccellente filosofia e legge. Sulla base di questa premessa, l'Autore rievoca i suoi anni di formazione di dottorato e la fase iniziale dello studio della storia del pensiero giuridico sotto la direzione di Guido Fassò, forse il più vichiano dei "iusfilosofi" italiani. Infine, rivendica l'importanza di Vico per la moderna Teoria del Diritto, giacché al pensatore napoletano dobbiamo, tra l'altro, il suo importante contributo alla dottrina dell'esperienza giuridica, i suoi risultati fondamentali per il rinnovamento della legge naturale attraverso la dimensione storica, così come l'influenza della sua opera giuridica per la riabilitazione della topica e la metodologia del diritto.

Parole ChiAve: Vico, $350^{\circ}$ Anniversario, Teoria del Diritto; esperienza giuridica; Diritto naturale; Storia della Filosofia del Diritto; topica; metodologia del diritto, G. Fassò, F.H. Llano Alonso.

Este artículo responde a una invitación expresa por parte de la Dirección de la Revista para este volumen especial por el $350^{\circ}$ Aniversario del nacimiento de G. Vico, habiendo superado los criterios de valoración y del proceso de aceptación. 
iambattista Vico es uno de los clásicos de la historia del pensamiento más germinales y sugestivos para la iusfilosofía de la segunda mitad del siglo XX. En efecto, tanto la doctrina de la experiencia jurídica, como el iusnaturalismo de contenido histórico, encuentran su inspiración en motivos tan netamente viquianos como la idea del diritto naturale che corre in tempo, y el diritto naturale delle genti, entendido como experiencia histórica y jurídica que, a juicio del genial pensador napolitano, es donde se debe buscar la razón última de la juridicidad. Para una generación de ilustres filósofos del Derecho italianos formados entre el idealismo, el historicismo y el iusnaturalismo -desde Giuseppe Capograssi a Felice Battaglia- los presupuestos de la filosofía de la Scienza nuova seconda, y de modo particular el aforismo verum ipsum factum que es sintetizado finalmente en el binomio verum-certum, influyen en la reacción frente al cientificismo, el formalismo jurídico y el reduccionismo iuspositivista imperantes en la Filosofía del Derecho decimonónica.

Resumiendo estos términos cruciales de la filosofía viquiana, podría decirse que si lo "verdadero" nace de la conformidad de la mente con el orden de las cosas, lo "cierto" es, al mismo tiempo, producto de la conciencia sensorial y, por ende, según se afirma en De uno universi iuris et principio et fine uno (1720): «ut autem verum constat ratione, ita certum nititur auctoritate». Así pues, la autoridad humana se supedita a la fuerza de la verdad o la razón, fundamento esencial de toda virtud que garantiza un minimum de justicia, materializando de este modo el único principio y fin del Derecho natural. En este sentido, como comenté en un trabajo anterior publicado en esta misma revista sobre el Derecho en Vico, ${ }^{1}$ la triple ecuación compuesta por los tres binomios filosofía-filología, verum-certum y ratio-auctoritas tendrían su equivalencia iusfilosófica en el binomio Derecho natural-Derecho positivo. En otras palabras: pese a ser elaborado por el hombre, y prescindiendo de su aparente arbitrariedad e irracionalidad, el Derecho positivo participa de la "veracidad" del Derecho natural, cuyas notas características más relevantes son la universalidad y la racionalidad. Este principio regulador de la vida de los pueblos se realiza y actúa en la historia, informando los ordenamientos jurídicos de las diferentes naciones, las cuales consiguen aprehender lo universal desde lo particular, movidos por diversas necesidades o utilidades, y orientándose por los designios de la Providencia. Este motivo especifica el sentido de la expresión "Derecho natural" auspiciada por Vico desde 1720 (coincidiendo con la fecha de publicación del De uno).

La trascendencia iusfilosófica de Giambattista Vico se pone de manifiesto si se considera la repercusión que en los últimos tiempos ha tenido su pensamiento

1. Cuadernos sobre Vico, n. 9/10, 1998, p. 160. 
en el desarrollo de la moderna Teoría del Derecho, constituyendo sus múltiples y variadas aportaciones científicas un rico filón que contribuye en buena medida a revitalizar los más surtidos estudios iusfilosóficos, posibilitando, por ejemplo, la propuesta de un modelo intermedio entre las antagónicas posturas mantenidas desde el iusnaturalismo de signo católico y el positivismo lógico-formal, influyendo en el actual debate sobre la racionalidad jurídica y la teoría de la argumentación en el Derecho o, también, sirviendo como punto de partida a las nuevas propuestas teóricas que pretenden revalorizar la tópica jurídica.

Uno de los iusfilósofos en los que más se puede apreciar la impronta de Vico es, precisamente, el autor que fue objeto de mi tesis doctoral: Guido Fassò (Bolonia, 1915-1974). Discípulo del también viquiano Felice Battaglia, Fassò se consagraría al estudio de la Filosofía del Derecho después de haber explorado a fondo los temas centrales de la filosofía viquiana, y de manera muy especial centró su atención en el análisis de la problemática jurídica abordada por el pensador napolitano en obras de referencia para los historiadores de la filosofía jurídica como De antiquissima Italorum sapientia ex lingua e latina e originibus eruenda (1710); la segunda parte de Il diritto universale (De constantia iurisprudentis, 1721); su Autobiografía (Vita, 1725-1728) o la Scienza nuova seconda (1730). Como el propio Fassò confiesa en su libro La storia come esperienza giuridica (1953), desde su juventud se sintió fascinado por la cantidad de interrogantes que le suscitaron sus lecturas viquianas, hecho que le animaría posteriormente a examinar a fondo el problema del Derecho en relación con el mundo empírico y le ayudaría a decantarse hacia un historicismo idealista que, con el tiempo, le conduciría hasta el descubrimiento de la doctrina de la experiencia jurídica. Para el que fuera catedrático de Filosofía del Derecho de la Universidad de Bolonia, la experiencia se halla preñada de fenómenos naturales e históricos. Esa multiplicidad fenoménica hace que la realidad empírica se nos aparezca como un continuum flumen donde se suceden hechos particulares y concretos que generan en nosotros el convencimiento de que lo acaecido en el pasado habrá de repetirse indefectiblemente en el futuro. Por consiguiente, para Fassò, tanto en el plano natural como en el histórico concurren la relatividad y la multiplicidad, siendo las leyes correspondientes a ambas esferas el producto de la actividad abstrayente o esquemática de la razón, la cual establece vínculos que enlazan los diferentes datos que forman parte de nuestra propia experiencia.

Como estudioso de la Historia de la Filosofía del Derecho, Fassò era perfectamente consciente de que la integración de la experiencia jurídica dentro de la historia ya había sido sugerida originalmente por Vico en su Scienza nuova, según se desprende de las siguientes palabras:

«la experiencia que es jurídica en tanto que es integral experiencia histórica, entendiendo el Derecho como forma necesaria y natural de la historia, de aquella historia a la cual Vico, con su lenguaje de filó- 
sofo poeta, le gustaba, para desesperación de sus intérpretes [...] llamar en la Scienza nuova "Derecho natural de las gentes"»."

Cuando escribía estas palabras, Fassò empezaba a vislumbrar lo que suponía participar del concepto viquiano de diritto naturale delle genti: básicamente, admitir la existencia de un Derecho natural mutable, racional e histórico que durante siglos habría desempeñado la función de educar a los hombres en su convivencia cotidiana. Esta "conversión" al iusnaturalismo histórico por parte de Fassò no se haría firme hasta 1964, el año de publicación de dos obras esenciales de su bibliografía: Il diritto naturale y La legge della ragione. En efecto, la importancia que para Fassò tuvo la concepción histórica del Derecho natural defendida por Vico se pondría de manifiesto en estos dos libros, donde efectuaba una revisión de su orientación crítica respecto al clásico concepto de "Derecho natural", descubriendo de paso que la posibilidad de compatibilizar el iusnaturalismo racionalista con las doctrinas historicistas o positivistas era perfectamente factible.

En uno de sus últimos libros, Vico e Grozio (1971), Fassò volvería a reconocer la influencia decisiva que tuvo en el desarrollo de su formación iusfilosófica el pensamiento jurídico de Giambattista Vico. Esta circunstancia, unida a las características inherentes al periodo de gestación de su filosofía, marcada por la crisis del idealismo imperante en la Italia de principios de siglo XX, llevó a Fassò a desconfiar de todo abstraccionismo intelectualista, del positivismo normativista y del objetivismo naturalista de autores como Gurvitch, Hauriou o Santi Romano. Su aversión al racionalismo se consolidó en una opción alternativa encarnada por el historicismo, que se combinaba con una convicción gnoseológica meta-ética, no-cognoscitivista y emotivista del Absoluto. Precisamente el anti-racionalismo de Fassò le impulsaría a restaurar la figura de Hugo Grocio (uno de los cuatro autores más inspiradores para Vico, junto a Platón, Tácito y Bacon). En la relación Grocio-Vico hallaría Fassò el nexo entre la razón y la historia que le serviría para implantar un embrión metodológico del que extraería con posterioridad el hilo conductor de la tradición iusnaturalista racionalista, cuyo recorrido completo se puede seguir en su célebre Storia della filosofia del diritto, obra de tres volúmenes que se ocupan de la Filosofía del Derecho de la Antigüedad y Edad Media (1966); de la Edad Moderna (1968); y de los siglos XIX y XX (1970), respectivamente.

De cuanto antecede no debería concluirse que Fassò compartía la tesis viquiana de la historicidad y la creatividad del espíritu, postulados por otra parte idealistas, porque frente a esta postura Fassò anteponía y reivindicaba la función reguladora de la razón humana, evitando esa propensión de la teoría grociana a pro-

2. G. FAssò, La storia come esperienza giuridica, Giuffrè, Milán, 1953, p. 12. [Nueva edición en Rubbettino, Soveria Mannelli, 2016]. 
pugnar un "sujeto o yo absoluto" en el que se disolvería el mismo Derecho. Por este motivo sería también erróneo pensar en un excesivo recelo por parte de Fassò hacia la razón, puesto que esta constituyó para el iusfilósofo boloñés una piedra angular en la elaboración de un proyecto iusnaturalista renovado, moderno y alternativo al incipiente iuspositivismo defendido en la segunda posguerra por autores como Uberto Scarpelli o Norberto Bobbio. Sin embargo, donde Fassò sí se encuentra claramente en deuda con el filósofo napolitano es en su visión de la historia como concreta racionalidad. Arrancando de esta idea, Fassò se adentraría en el mundo de la Filosofía del Derecho, profundizando a partir de entonces en una introspección histórica que el carácter problemático y dilemático del Derecho y la experiencia jurídica pudieran plantearle como filósofo y como jurista. Así pues, si convenimos que los términos "razón" e "historia" no son recíprocamente excluyentes y que es precisamente en este binomio donde encuentra aposento el proyecto iusnaturalista delineado por Guido Fassò, estaremos en disposición de apreciar la relevancia de la argumentación jurídica y la racionalidad práctica ante los problemas que tanto la hipertrofia legislativa como las lagunas del sistema normativo pueden ocasionar a los destinatarios del Derecho. Así pues, también en la restauración de la tópica y la metodología jurídica cabe presumir la ascendencia intelectual y filosófica de Giambattista Vico, uno de los clásicos de la historia del pensamiento jurídico que más ha contribuido a renovar los estudios de la Filosofía del Derecho contemporánea (precisamente por la condición germinal y sugerente de su sistema de ideas).

Ha transcurrido casi un cuarto de siglo desde que publiqué mi primer escrito dedicado a los estudios viquianos de Guido Fassò, precisamente en la revista Cuadernos sobre Vico, ${ }^{3}$ y gracias a la cortesía de su director, el Prof. Dr. José Manuel Sevilla Fernández. Al echar la vista atrás y hacer un balance retrospectivo del trabajo realizado a lo largo de este tiempo, debo admitir que tanto en mi vocación como investigador de la historia del pensamiento jurídico, como en el desempeño cotidiano de mis tareas docentes como profesor de la Teoría del Derecho y de Filosofía del Derecho, la figura y el pensamiento de Vico han sido y son para mí un permanente punto de apoyo y un argumento de autoridad para explicar a mis alumnos la concepción tetradimensional del Derecho como experiencia jurídica (el Derecho entendido en sus cuatro dimensiones axiológica, sociológica, normativa e histórica), y justificar mi alineamiento dentro de la corriente doctrinal del iusnaturalismo deontológico y crítico (de contenido histórico).

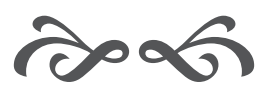

3. Cuadernos sobre Vico 5/6, 1995/1996, pp. 67-82. 
<smiles>[As]</smiles> 